\title{
Presentation modality affects false memory
}

\author{
REBEKAH E. SMITH and R. REED HUNT \\ University of North Carolina, Greensboro, North Carolina
}

\begin{abstract}
Roediger and McDermott (1995) rejuvenated interest in Deese's (1959) paradigm for producing reliable intrusions and false alarms. Using this paradigm in three experiments, we demonstrated that visual study presentation dramatically reduces the rate of false memories. Only auditory study presentation resulted in equal production of studied and critical items. Correct recall and recognition were unaffected. The suggestion that visual presentation provides a means for discriminating between false and true memories was supported by Experiment 3: Pleasantness rating of study items significantly reduced the creation of false memories regardless of modality.
\end{abstract}

False memories can be created reliably by presenting lists of words that are all strong associates of a nonpresented word. The strong associate usually is recalled and recognized at the same rate as that for presented items. This laboratory technique for invoking predictable intrusions or false alarms has received considerable attention in the literature following Roediger and McDermott's (1995) replication and extension of Deese's (1959) work.

The experiments that we report here were motivated by an interest in the effects of item-specific processing of list words on recall of the critical, nonpresented associates. Item-specific processing is assumed to affect a discriminative process of distinctiveness at retrieval. Thus, item-specific processing of list words may facilitate discrimination of those items from nonpresented items and thereby reduce the level of false memory. We began this research by using a powerful item-specific study task that requires subjects to report one thing that is different about an item from all other items in the list (Hunt \& Smith, 1996). Unfortunately, we were unable to evaluate the proposed role of distinctive processing because we failed to create false memories at a rate equivalent to true memories in the control condition of that experiment, a condition comparable to the critical conditions of Roediger and McDermott (1995). As it happened, we had inadvertently changed an apparently important aspect of the experimental paradigm: modality of list presentation. Our items were presented via a computer monitor, and the results showed unusually low levels of intrusions in conditions that normally yield critical intrusions at the same rate as that for actually studied items. A search of

We thank Robert Crowder, Arthur Glenberg, David Payne, and Henry Roediger for helpful comments on a previous version of the manuscript. This research was supported in part by funds from the Research Council of the University of North Carolina at Greensboro granted to the second author. Correspondence may be addressed to R. E. Smith or R. R. Hunt, Department of Psychology, University of North Carolina at Greensboro, Greensboro, NC, 27412 (e-mail: resmith@hamlet.uncg. edu or huntrr@hamlet.uncg.edu). the literature supported our suspicions that visual presentation was the cause of this reduction. ${ }^{1}$

All published reports of created memories obtained with the Roediger and McDermott/Deese paradigm, with one exception, have used an auditory list presentation (Johnson et al., 1997; Mather, Henkel, \& Johnson, 1997; McDermott, 1996; Norman \& Schacter, 1997; Payne, Elie, Blackwell, \& Neuschatz, 1996; Read, 1996; Schacter et al., 1996; Schacter, Verfaellie, \& Pradere, 1996). The one exception to the use of auditory presentation is a study by Robinson and Roediger (1997) in which only visual presentation was used. The rates of critical item intrusions were noticeably lower in this study than the rates in other published reports. For instance, Robinson and Roediger reported probabilities of false recall of .31 and .30 for 15 -word lists as compared with a false recall rate of .55 for 15 -word lists reported by Roediger and McDermott (1995).

Although the primary goal of our paper is to report the empirical finding of a modality effect on false memories, we shall speculate about a possible explanation for this effect. This speculation is grounded in the framework that explains memorial phenomena in terms of the interaction of distinctive and relational processing. Specifically, we propose that visual presentation provides a better means for discriminating between studied items and the related critical items than does auditory presentation. If this is the case, we should be able to enhance discrimination through some other mechanism even when auditory presentation is used. In the third experiment, we investigated this possibility and obtained favorable results.

\section{EXPERIMENT 1}

In the first experiment, we used a modified version of the Deese paradigm, in which the different lists of associated words were presented blocked in one list followed by a recall test. Given previous research showing that false memories can be created at a rate equal to that of true memories using such a technique (McDermott, 1996), we expected to replicate the effect with auditory presenta- 
tion. However, if presentation modality affects the discrimination of presented and critical items, we should not find equivalent production of the studied items and critical items in recall following visual presentation, and the production of critical lures should interact with modality of presentation.

\section{Method}

Subjects and Design. Twenty introductory psychology students participated for credit. The between-subjects manipulation of study modality, visual or auditory, was combined with the within-subjects manipulation of item type, which also had two levels: studied (items actually seen or heard at study) or critical (the high associates of the studied items that were not actually presented at study).

Materials and Equipment. We randomly chose 10 critical items from the lists presented in Roediger and McDermott (1995). The 5 highest associates of each critical item made up the 50-item study list. The studied items were presented blocked during study, always going from the 1 st to the 5 th associate. The words were read aloud by an experimenter or presented on a computer monitor.

Procedure. The experiment consisted of two phases: a study phase and a test phase, separated by a brief period in which the subjects completed credit forms. Study presentation rate was one word/1.5 sec in both the auditory and the visual conditions. At test, 3 min were allowed for free recall, with the instructions that the subjects should be reasonably sure that the words were in fact ones that they had either heard or seen.

\section{Results and Discussion}

The mean proportions of words produced on the free recall test are shown in Table 1 as a function of modality and item type. Modality had no reliable effect $[F(1,18)=$ $\left.1.42, M S_{\mathrm{e}}=.01\right]$, and the effect of item type $[F(1,18)=$ $\left.20.84, M S_{\mathrm{e}}=.01\right]$ was qualified by a reliable interaction of the two variables $\left[F(1,18)=6.43, M S_{\mathrm{e}}=.01\right](\alpha=$ $.05)$. Individual comparisons indicated that critical and studied item recall did not differ reliably following auditory presentation $[t(9)=-1.63]$, but following visual presentation, studied items were twice as likely to be recalled as critical items $[t(9)=-4.54]$. Moreover, critical intrusions were reliably higher in the auditory than in the visual condition $[t(18)=2.76]$. The same trend was evident in the noncritical intrusions, but insufficient power was available to detect differences. The differences in intrusion rates were not due to shifts in criteria, given the lack of difference between visual and auditory conditions on studied items $[t(18)=-.72]$.

The interaction of modality and item type could occur because visual study presentation reduces the likelihood of thinking of the critical item either at study or at test or because visual presentation increases the subjects' ability to discriminate items that they thought of at study from those that had actually been presented. If the interaction of modality and item type is solely due to a reduced likelihood of production of an item at retrieval, then the interaction of modality and item type should disappear when a recognition test is used. Alternatively, if recognition performance yields the same interaction, the result would implicate a contribution of study modality to the discrimination between critical and studied items.

\section{EXPERIMENT 2}

The primary purpose of the second experiment was to generalize the finding of a modality effect to the use of longer lists of associates and a recognition test. In order to do so while also making a direct comparison with previous reports of created false memories, we replicated Experiment 1 of Roediger and McDermott (1995) with the additional manipulation of modality. This design includes separate free recall tests after each individual list presentation and a final recognition test. The use of longer lists is important, because false alarm rates increase when more items related to the lures are presented at study (see, e.g., Robinson \& Roediger, 1997). The interaction of modality and item type in our first experiment could be an artifact of the relatively short lists of associates used.

Table 1

Recall and Recognition of Studied and Nonstudied Items

\begin{tabular}{|c|c|c|c|c|c|c|c|c|c|c|c|c|}
\hline \multirow[b]{4}{*}{ Experiment } & \multirow[b]{4}{*}{ Task } & \multirow[b]{4}{*}{ Modality } & \multicolumn{10}{|c|}{ Item Type } \\
\hline & & & & & & & \multicolumn{4}{|c|}{ False Alarms* } & \multirow{2}{*}{\multicolumn{2}{|c|}{$\begin{array}{l}\text { Noncritical } \\
\text { Intrusions }\end{array}$}} \\
\hline & & & \multicolumn{2}{|c|}{ Studied* } & \multicolumn{2}{|c|}{ Critical* } & \multicolumn{2}{|c|}{ Related } & \multicolumn{2}{|c|}{ Unrelated } & & \\
\hline & & & $M$ & $S D$ & $M$ & $S D$ & $M$ & $S D$ & $M$ & $S D$ & $M$ & $S D$ \\
\hline \multirow[t]{2}{*}{1} & & Auditory & .26 & .10 & .21 & .10 & & & & & 2.30 & 2.67 \\
\hline & & Visual & .29 & .09 & .11 & .06 & & & & & 1.10 & .88 \\
\hline \multirow[t]{4}{*}{2} & Recall & Auditory & .65 & .08 & .42 & .14 & & & & & 1.10 & 2.47 \\
\hline & & Visual & .72 & .07 & .22 & .24 & & & & & .04 & .60 \\
\hline & Recognition & Auditory & .88 & .11 & .82 & .27 & .11 & .15 & 01 & .26 & & \\
\hline & & Visual & .85 & .12 & .45 & .27 & .10 & .32 & .01 & .26 & & \\
\hline \multirow[t]{4}{*}{3} & & Auditory SE & .29 & .08 & .33 & .19 & & & & & .45 & .83 \\
\hline & & Auditory PR & .32 & .06 & .20 & .21 & & & & & .15 & .37 \\
\hline & & Visual SE & .33 & .09 & .18 & .13 & & & & & .20 & .41 \\
\hline & & Visual PR & .32 & .08 & .10 & .11 & & & & & .20 & .52 \\
\hline
\end{tabular}

* Mean proportions. †Mean absolute numbers 


\begin{abstract}
Method
Subjects and Design. Twenty volunteers participated in this experiment for course credit. The design was the same as that of Experiment 1 a between-subjects manipulation of modality and a within-subjects manipulation of item type.

Materials. We used the same six critical items selected by Roediger and McDermott (1995, Experiment 1), because these items produced the highest levels of false remembering in Deese's report. The first 12 associates of the 6 critical items made up the study list. Subjects either saw the words on slides or heard a tape of the words.

The 42 words on the recognition test were blocked into six sets. Each block began with the highest associate and ended with the critical word. The other 5 words were as follows: an additional study item randomly selected from Positions 2-6 on the list of associates; 2 related lures, selected from Positions 14 and 15 of the associate list, but not shown during study; and 2 unrelated lures selected from Position 14 or 15 of two different nonstudied associate lists. The construction of test lists matches that used by Roediger and McDermott (1995).

Procedure. Six study/free-recall phases were followed by a final recognition test. Subjects were instructed that they would hear/see a series of word lists, and that at the end of each list, they would hear/see the word "recall" and should write as many words as they could remember from the previous list, but not to guess. As in Roediger and McDermott's (1995) study, they were instructed to write the last few words first and then recall the rest in any order. Items were presented at a rate of one word every $1.5 \mathrm{sec}$, and a maximum of $2.5 \mathrm{~min}$ was allowed for recall. Following the last free recall test, the subjects were given a self-paced old/new recognition test.
\end{abstract}

\section{Results and Discussion}

Recall. Recall scores, averaged across the six tests, are shown in Table 1. As in the first experiment, modality exerted no main effect $\left[F(1,18)=2.39, M S_{\mathrm{e}}=.02\right]$, but item type was reliable $\left[F(1,18)=53.43, M S_{\mathrm{e}}=.02\right]$. Most importantly, item type interacted with modality of presentation $\left[F(1,18)=7.13, M S_{\mathrm{e}}=.02\right]$. The interaction was a result of the much larger difference between critical and studied items following visual presentation $[t(9)=-6.31]$ than following auditory presentation $[t(9)=-3.79]$, although both differences were reliable. Not only is the difference between critical and studied items larger following visual presentation, but a comparison of critical item recall for visual and auditory groups shows a reliable modality effect on the creation of false memories $[t(18)=$ 2.30]. The noncritical intrusions followed the same pattern, but again the small number of these intrusions precluded meaningful analysis. Thus, the recall data replicate the findings of Experiment 1.

Recognition. The recognition data are presented in Table 1, and analysis of these data confirmed that the modality effect also occurred in recognition. Item type reliably interacted with modality $\left[F(1,18)=6.21, M S_{\mathrm{e}}=\right.$ $.05]$, qualifying separate main effects of item type $[F(1,18)$ $\left.=11.17, M S_{\mathrm{e}}=.05\right]$, and modality $[F(1,18)=10.12$, $\left.M S_{\mathrm{e}}=.04\right]$. The interaction of modality was even more dramatic on the recognition test than on the recall tests; subjects in the visual group were much more likely to call a studied item old than to call a critical item old $[t(9)=-3.97]$, but subjects in the auditory group were equally likely to call studied and critical items old $[t(9)=$ $-.627]$. As with the recall results, false recognition of critical items was reliably higher following auditory than following visual presentation $[t(18)=3.04]$. False alarms to related lures were also greater for auditory than for visual presentation, but unrelated lures did not differ. Thus, the data clearly show that production of false memories in recognition is sensitive to mode of original list encoding.

One objection to the preceding conclusion is that the modality effect on recognition was an artifact of the modality effect on the intervening free recall tests. An analysis of false recognition conditionalized on failure to recall the items suggested that the concern was unwarranted. Considering only the critical items that were not recalled on the intervening free recall tests, the mean probability of falsely recognizing the nonrecalled critical items following auditory presentation $(M=.73, S D=$ .35) was significantly higher than the mean probability following visual presentation $(M=.31, S D=.31)[t(18)=$ 2.81]. Thus, regardless of whether or not items were recalled, false recognition of critical items was significantly reduced by visual presentation relative to auditory presentation at encoding.

The modality effect on false memories in recognition suggests that visual presentation does not simply reduce the likelihood of producing the critical items at retrieval. When presented with the critical items on the recognition test, subjects in the visual group were still less likely to say that the critical items were part of the list. Therefore, visual presentation must either prevent the critical words from coming to mind at study or provide a better means of distinguishing between things that are internally generated and things that are externally presented.

\section{EXPERIMENT 3}

The first two experiments demonstrate that visual study presentation of associatively related lists dramatically reduces the creation of false memories, relative to auditory study presentation in both recall and recognition. Although subjects did falsely recall and recognize some critical items following visual presentation, the rate of production and recognition of critical items was far below the rate for studied items. Equivalent response rates across item types occurred only when subjects heard the list.

The influence of modality could be due to changes in what comes to mind at study, changes in what comes to mind at test, or changes in subjects' ability to discriminate internal and external sources. Although our data do not provide definitive evidence, it seems unlikely that the modality effect would be due solely to what comes to mind at test. There is no reason to suspect differential strategy use in free recall as a function of presentation modality. Furthermore, visual presentation also reduced false memories on the recognition test, where each item must be considered. Likewise, it seems unlikely that presentation modality would alter what comes to mind at study. We are not aware of any evidence that associations are modality sensitive. 
More plausible is the possibility that the critical lures come to mind during presentation of the study list, much in the spirit of Underwood's (1965) concept of implicit associative responses. In the absence of differential processing of the studied and critical items, the critical items will not be discriminated from studied items if they come to mind at test. Modality of study presentation provides one such dimension of differential processing. Visual processing differs from auditory processing, and on the speculative assumption that visual perception is less like thought than is auditory perception, critical items would be more easily discriminated from list items following visual presentation than following auditory presentation of list items. The implication is that other forms of differential study processing should reduce the level of false recall. We tested his hypothesis in the third experiment, by comparing the effects of a pleasantness rating orienting task with standard instructions.

In the third experiment, we followed the same procedures as those of the first experiment, but with the addition of a pleasantness rating study condition to both the auditory and visual conditions. Since pleasantness rating requires consideration of the specific meaning of each word, and since that meaning is different for each word, pleasantness rating encourages item-specific processing of a form that should be useful for discrimination among items at retrieval. Thus, we predicted a lower level of false recall following pleasantness rating of the study list than following standard instructions.

\footnotetext{
Method

Subjects and Design. Twenty volunteers, participating for course credit, were randomly assigned to each of four experimental groups resulting from the manipulation of study modality (auditory, visual) and study task (standard encoding, pleasantness rating).

Materials and Equipment. The word lists from Experiment 2 were either shown on slides or read aloud by an experimenter

Procedure. The procedure matched that of Experiment l, except for the additional instructional manipulation and an increase in presentation time to $2 \mathrm{sec}$. Half of the subjects were given intentional study in structions and the other half were given incidental instructions. The incidental instructions requested that each word be rated for pleasantness on a scale of $1=$ unpleasant to $5=$ pleasant . Recall instructions were the same as in Experiment 1 for all conditions.
}

\section{Results}

The mean proportions of words produced on the free recall test are shown in Table 1 as a function of modality, study task, and item type. The reliable effects of modality $\left[F(1,76)=6.00, M S_{\mathrm{e}}=.02\right]$, study task $[F(1,76)=4.78$, $\left.M S_{\mathrm{e}}=.02\right]$, and item type $\left[F(1,76)=34.15, M S_{\mathrm{e}}=.02\right]$ were qualified by reliable interactions of modality and item type $\left[F(1,76)=13.52, M S_{\mathrm{e}}=.02\right]$ and of study task and item type $\left[F(1,76)=7.29, M S_{\mathrm{e}}=.02\right]$. Neither the interaction between modality and study task $[F(1,76)=$ $\left..01, M S_{\mathrm{e}}=.02\right]$ nor the three-way interaction $[F(1,76)=$ $\left.1.39, M S_{\mathrm{e}}=.02\right]$ was significant. Separate analyses were conducted for the two item types to investigate the significant interactions.
The proportion of studied items correctly recalled was examined first. The manipulations of modality $[F(1,76)=$ $\left.1.49, M S_{\mathrm{e}}=.01\right]$ and study task $\left[F(1,76)=0.18, M S_{\mathrm{e}}=\right.$ $.01]$ did not influence the production of studied items, nor was the interaction of the two variables significant $\left[F(1,76)=1.59, M S_{\mathrm{e}}=.01\right]$. Similarly, critical item recall was not affected reliably by the interaction of modality and study task $\left[F(1,76)=0.45, M S_{\mathrm{e}}=.03\right]$. In contrast, both modality $\left[F(1,76)=11.26, M S_{\mathrm{e}}=.03\right]$ and study task $\left[F(1,76)=7.21, M S_{\mathrm{e}}=.03\right]$ influenced the likelihood of producing critical items on the recall test. Thus, while studied items were unaffected by our manipulations, critical item production was influenced by modality of presentation and by the type of instructions given to the subjects at encoding.

The exact nature of this influence was investigated with one-tailed independent $t$ tests, which showed that critical item production was significantly decreased by visual presentation relative to auditory presentation for both the pleasantness rating $[t(38)=1.85]$ and standard encoding $[t(38)=2.93]$ groups. Likewise, pleasantness rating decreased critical item production relative to standard encoding, regardless of whether presentation was auditory $[t(38)=1.95]$ or visual $[t(38)=1.97]$. Intrusion of related distractors also was higher following auditory presentation with standard instructions than in other conditions, but again the small number of related and unrelated item intrusions precluded meaningful analysis.

Finally, within-group comparisons contrasted critical item production and studied item production. No reliable difference in recall of studied and critical items $[t(19)=$ 0.75 ] occurred following auditory presentation with standard encoding instructions. In contrast, both the visual presentation pleasantness rating group $[t(19)=-7.04]$ and the visual presentation standard encoding group $[t(19)=-4.35]$ recalled reliably more studied items than critical items. Collapsing over modality, critical items were less likely to be produced than studied items following pleasantness rating than following standard instructions $[t(19)=-2.73]$.

\section{Discussion}

The results of Experiment 3 replicated the modality effect of Experiments 1 and 2 . In comparison with auditory presentation, visual presentation significantly decreased the likelihood of producing critical items on a recall test. Furthermore, subjects who performed a pleasantness rating task at study were less likely to produce critical items on the recall test than subjects who intentionally tried to remember the words. Only the control group, auditory presentation with standard instructions, produced critical items at a rate that was equivalent to the rate of correct recall of studied items. Both visual presentation and the pleasantness rating task resulted in a critical intrusion rate below the rate of studied item production.

The lack of an effect of pleasantness rating on study list items should not be seen as inconsistent with the enormous literature showing benefits of semantic orienting tasks. Note that the comparisons in this experiment were between pleasantness rating and intentional memory instructions. Previous research has found comparable perfor- 
mance following these two study conditions (e.g., Hyde \& Jenkins, 1969).

\section{GENERAL DISCUSSION}

The three experiments reported here demonstrate the existence and reliability of a modality effect on false memory in the Roediger and McDermott (1995) paradigm. In comparison with auditory presentation, visual presentation of study items reduces the level of false memory. The fact that the modality effect occurs in recognition suggests that false memory is not just a product of associative activation at retrieval in recall, but rather that the critical item probably comes to mind at study as well as at test (Roediger \& McDermott, 1995; Underwood, 1965). If the critical item does come to mind at study, it then is part of the encoding experience, much as categorical information is part of the experience of encoding a block of category instances. Thus, mere presence on the study list is not sufficient for subjects to discriminate between a list item and a critical lure. Successful discrimination requires processing along some dimension that differentiates the study item from the critical item, and speculatively, visual processing of the study items provides a better basis for differentiation than does auditory presentation. In support of this general idea, the results of Experiment 3 indicate that other dimensions of differential processing-in this case, pleasantness rating of the study list-also will reduce the rate of false memory.

Our interpretation of the data derives from the more general view of memory as determined by the processing of similarity and differences among elements of an event (Hunt \& McDaniel, 1993). In retrieval, differences are presumed to be important for discriminating among elements of an event, because the event is defined by similarity among the elements. For example, critical items and studied items in this paradigm share the property of having been experienced at encoding, and therefore, reinstating the similarity processing with the cue "Recall the study items" is insufficient for distinguishing critical and studied items. Differential processing of the items at study facilitates discrimination at retrieval and reduces the recall and recognition of critical items.

Existing evidence is congruent with various aspects of our interpretation. The assumption that visually driven processing is more discriminable from thought than is auditorially driven processing has not been directly tested in the reality monitoring literature, but Johnson, Nolde, and De Leonardis (1996) have reported that source monitoring is more highly correlated with visual detail than with auditory detail in the original event. Notice, however, that our assumption is that modality of presentation will be useful only to the extent that it differentiates among items. In the Roediger and McDermott (1995) paradigm, we would not predict a modality effect on studied items. This prediction is not only consistent with our results but also with those of Hashtroudi, Ferguson, Rappold, and Chrosniak (1988), who found that auditory study increased false alarms on a recognition test without influencing hits.

Our assumption about the importance of processing similarities and differences among items is also consistent with existing evidence. McDermott (1996) and Mather et al. (1997) found increased levels of critical item recall with blocked list presentation relative to random list presentation at study. Blocked presentation encourages relational processing, and in this case the relationship among items is the critical item. Therefore this item is brought to mind more readily than with random presentation.

Read (1996) reported that instructions to remember the order of presentation reduced the recall of critical items. Because information corresponding to serial order is different for each item, successful serial recall has been attributed to distinctive processing (Nairne, Neath, Serra, $\&$ Byun, 1997). Thus, Read's data are consistent with the importance of distinctive processing in reducing false recall.

Israel and Schacter (1997) discovered that false memory is less likely if the study materials are pictures rather than words. Nelson, Reed, and McEvoy (1977) argued that the picture superiority effect in memory is due to more elaborate sensory processing required by pictures, which in turn enhances the distinctiveness of pictures at retrieval. Thus, Israel and Schacter's data can be seen as congruent with our interpretation
However, one result reported by Israel and Schacter directly contradicts our data. Subjects in a control condition were given visual presentation of words, and the false memory effect was not reduced. Importantly, visual presentation was accompanied by simultaneous auditory presentation. Auditory presentation may have truncated visual processing of the word analogous to the reduction of sensory processing in the generation paradigm when semantic context is provided (Blaxton, 1988; Jacoby, 1983). Pictures, with their more elaborate sensory processing requirements, would be immune to the influence of simultaneous auditory presentation.

In summary, the Roediger and McDermott (1995) paradigm is designed to bring critical nonpresented items to mind at study. The cues provided by free recall instructions are then as likely to reinstate the critical items as the presented items unless some basis for differentiation occurs at study. The existence of a modality effect suggests that even subtle differences in processing of critical and presented items at study can service the distinctive processing in retrieval that is necessary to reduce false memory.

\section{REFERENCES}

BLAXTON, T. A. (1988). Investigating dissociations among memory measures: Support for the transfer appropriate processing framework. Journal of Experimental Psychology: Learning, Memory, \& Cognition, 15, 657-668.

BLAXTON, T. A. (1996). Distinguishing false from true in human memory. Neuron, 17, 191-194.

DEESE, J. (1959). On prediction of occurrence of particular verbal intrusions in immediate recall. Journal of Experimental Psychology, 58, 17-22.

Hashtroudi, S., Ferguson, S. A., Rappold, V. A., \& Chrosniak, L. D. (1988). Data-driven and conceptually driven processes in partialword identification and recognition. Journal of Experimental Psychology: Learning, Memory, \& Cognition, 14, 749-757.

HUNT, R. R., \& MCDANIEL, M. A. (1993). The enigma of organization and distinctiveness. Journal of Memory \& Language, 32, 421-445.

HunT, R. R., \& SMITH, R. E. (1996). Accessing the particular from the general: The power of distinctiveness in the context of organization. Memory \& Cognition, 24, 217-225.

Hyde, T. S., \& JENKINS, J. J. (1969). Differential effects of incidental tasks on the organization of recall of a list of highly associated words. Journal of Experimental Psychology, 82, 472-481.

ISRAEL, L., \& SCHACTER, D. L. (1997). Pictorial encoding reduces false recognition of semantic associates. Psychonomic Bulletin \& Review, $4,577-581$

JACOBY, L. L. (1983). Remembering the data: Analyzing interactive processes in reading. Journal of Verbal Learning \& Verbal Behavior, 22, 485-508

Johnson, M. K., Nolde, S. F., \& De Leonardis, D. M. (1996). Emotional focus and source monitoring. Journal of Memory \& Language, 35, 135-156.

Johnson, M. K., Nolde, S. F., Mather, M., Kounios, J., Schacter, D. L., \& CURRAN, T. (1997). The similarity of brain activity associated with true and false recognition memory depends on test format. Psvchological Science, 8, 250-257.

Mather, M., Henkel, L. A., \& Johnson, M. K. (1997). Evaluating characteristics of false memories: Remember/know judgments and memory characteristics questionnaire compared. Memory \& Cognition, 25, 826-837.

MCDermotr, K. B. (1996). The persistence of false memories in list recall. Journal of Memory \& Language, 35, 212-230.

Nairne, J. S., Neath, I., Serra, M., \& Byun, E. (1997). Positional distinctiveness and the ratio rule in free recall. Journal of Memory \& Language, 37, 155-166.

NeLson, D. L., REED, V. S., \& MCEvoy, C. L. (1977). Learning to order pictures and words: A model of sensory and semantic encoding. Journal of Experimental Psychology: Human Learning \& Memory, 3, 484-497.

NORMAN, K. A., \& SChaCter, D. L. (1997). False recognition in younger and older adults: Exploring the characteristics of illusory memories. Memory' \& Cognition, 25, 838-848. 
Payne, D. G., Elie, C. J., Blackwell, J. M., \& Neuschatz, J. S. (1996). Memory illusions: Recalling, recognizing, and recollecting events that never occurred. Journal of Memory \& Language, 35, 261-285. READ, J. D. (1996). From a passing thought to a false memory in $2 \mathrm{~min}$ utes: Confusing real and illusory events. Psychonomic Bulletin \& Review, 3, 105-111.

Robinson, K. J., \& RoEdiger, H. L., III (1997). Associative processes in false recall and false recognition. Psychological Science, 8, 231-237.

Reediger, H. L., III, \& McDermott, K. B. (1995). Creating false memories: Remembering words not presented in lists. Journal of Experimental Psychology: Learning, Memory, \& Cognition, 21, 803-814.

Schacter, D. L., Reiman, E., Curran, T., Yun, L. S., Bandy, D., MCDermotT, K. B., \& Roediger, H. L., III (1996). Neuroanatomical correlates of veridical and illusory recognition memory: Evidence from positron emission tomography. Neuron, 17, 267-274.
Schacter, D. L., Verfaellie, M., \& Pradere, D. (1996). The neuropsychology of memory illusions: False recall and recognition in amnesic patients. Journal of Memory \& Language, 35, 319-334.

UNDERWOOD, B. J. (1965). False recognition produced by implicit verbal responses. Journal of Experimental Psychology, 70, 122-129.

\section{NOTE}

1. Blaxton (1996) compared several neuroimaging studies and detected a pattern suggestive of the importance of modality of presentation.

(Manuscript received October 14, 1997; revision accepted for publication February 24, 1998.) 